\title{
Vibration of Natural Rock Arches and Towers Excited by Helicopter-Sourced Infrasound
}

\author{
Riley Finnegan ${ }^{1}$, Jeffrey R. Moore ${ }^{1}$, Paul R. Geimer ${ }^{1}$ \\ ${ }^{1}$ Department of Geology and Geophysics, University of Utah, Salt Lake City, 84112, USA
}

\section{Correspondence to: Riley Finnegan (riley.finnegan@utah.edu)}

\begin{abstract}
Helicopters emit high-power infrasound in a frequency range that can coincide with the natural frequencies of rock landforms. While a single previous study demonstrated that close-proximity helicopter flight was able to excite potentially damaging vibration of rock pinnacles, the effects on a broader range of landforms remain unknown. We performed a series of controlled flights at seven sandstone arches and towers in Utah, USA, recording their vibration response to helicopter-sourced infrasound. We found that landform vibration velocities increased by a factor of up to 1000 during close-proximity helicopter flight as compared to ambient conditions immediately prior, and that precise spectral alignment between infrasound and landform natural frequencies is required to excite resonance. We define admittance as the ratio of vibration velocity to infrasound pressure and recorded values up to $0.11 \mathrm{~mm} \mathrm{~s}^{-1} \mathrm{~Pa}^{-1}$. While our results demonstrate a strong vibration response, the measured velocities are lower than likely instantaneously damaging values. Our results serve

15 as a basis for predicting unfavorable degradation of culturally significant rock landforms due to regular helicopter overflights.
\end{abstract}

\section{Introduction}

Anthropogenic activity is increasingly shaping evolution of the natural environment over geologically brief timescales (Aarons et al., 2016; Cochran et al, 2013; Whyte, 2016). Motor vehicles, trains, and aircraft generate ground- and air-borne 20 vibration energy that may propagate over large distances, significantly altering the ambient vibration wavefield in some regions (Riahi and Gerstoft, 2015). Helicopters, however, are unique in that they have nearly limitless reach over the landscape and produce a range of sound energy during operation. Helicopters create "thickness noise," directional, narrowband infrasound emitted from the main rotor blades and strongest in the rotor plane (Schmitz and Yu, 1983), which while inaudible, is often the loudest sound produced and propagates over large distances (Cheremisinoff, 1994). This energy occurs in a narrow frequency band, the so-called blade pass frequency (and its overtones), which is set by the number of main rotor blades multiplied by the rotor revolution rate, and the resulting measured sound frequency is only subsequently altered by Doppler shift during flight (Doppler, 1842; Schmitz and Yu, 1983). These helicopter and other acoustic signals couple to the ground (Bass et al., 1980) and can be recorded as Raleigh waves using seismometers (Novoselov et al., 2020). 
The corresponding seismic signals resemble tremors produced by volcanoes (Eibl et al., 2015) and researchers have used seismic measurements of helicopter-sourced infrasound to investigate flightpaths near airfields (Meng and Ben-Zion, 2018), volcanoes (Eibl et al., 2017 and Eibl et al., 2015), and glaciers (Podolskiy et al., 2017).

Past studies have assessed the effects of helicopter-sourced infrasound on people and engineered structures (Broner, 1978; Hanson et al., 1991; Schomer and Neathammer, 1985; Wagner, 1978); however, few have analyzed the effects of directional infrasound generated by thickness noise on the vibration response of natural landforms and other cultural features (King, 1996, 2001). A single previous study (King, 2001) reported that a helicopter hovering $10 \mathrm{~m}$ from a rock pinnacle was capable of exciting vibrations with measured peak velocity of several $\mathrm{mm} \mathrm{s}^{-1}$, which is in the range considered as potentially damaging for geologic features and ancient monuments (Whiffin and Leonard, 1971; Hanson et al., 1991; Hendricks, 2002; Volpe, 2014; Moore, 2018). When the frequency of an energy source-in this case, helicopter-sourced infrasoundprecisely matches the fundamental or higher-order natural frequencies of a structure, resonance is excited and vibration amplitudes increase markedly, potentially generating damage in the structure (Fujino et al., 1993). Geologic structures such as natural arches and towers are abundant in the southwestern United States and are also found in other environments around the world. As helicopter flights are increasingly common in these areas (National Park Service 2016, 2020), additional studies are needed to characterize the effects of helicopter activity, especially sustained activity over many years, on structural degradation of these valued landforms.

45 Here, we explore the vibration response of natural sandstone arches and towers (or hoodoos) to helicopter-sourced infrasound. We performed a suite of field measurements where we recorded landform vibration response during controlled helicopter flights. We assessed landforms of different sizes and geometries and varied helicopter maneuvers. We found that infrasound emitted from helicopters can excite resonance of natural landforms, albeit at peak velocities generally lower than those thought to produce instantaneous damage. Our results have implications for the management, conservation and preservation of culturally valuable rock landforms.

\section{Study Sites}

We selected 4 arches and 3 towers for study during helicopter flights, all in Utah, USA (Fig. 1, Table 1). These landforms are on the traditional lands of the Hopi, Navajo, Southern Paiute, Ute, and Zuni peoples, and similar arches and towers have cultural significance to these populations (Stoffle et al., 2016). Additionally, many arches and towers serve as tourist

55 attractions in the desert southwest and see millions of visitors each year (National Park Service, 2021). The selected arches have spans of between 3 and $12 \mathrm{~m}$ and the hoodoos are $4 \mathrm{~m}$ tall (Table 1). Arsenic Arch and Squint Arch are formed in 

Formation, and Two Bridge is formed in sandstone of the Pink Member of the Claron Formation. The hoodoos are part of the Little Egypt outcrop formed in Entrada Sandstone.
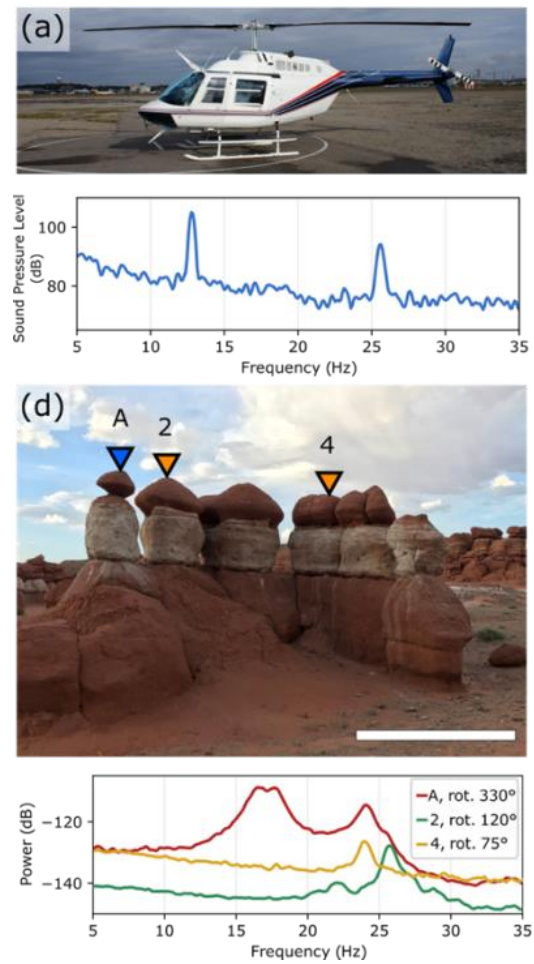
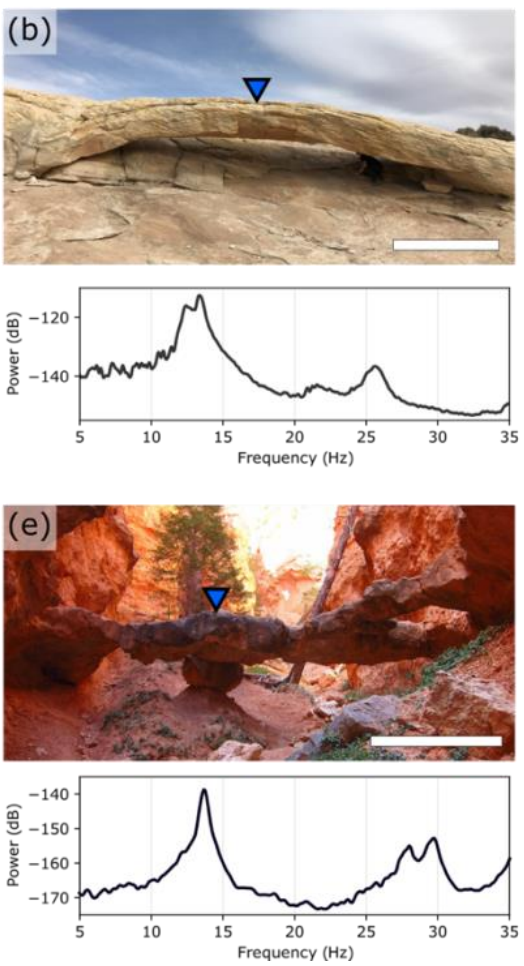
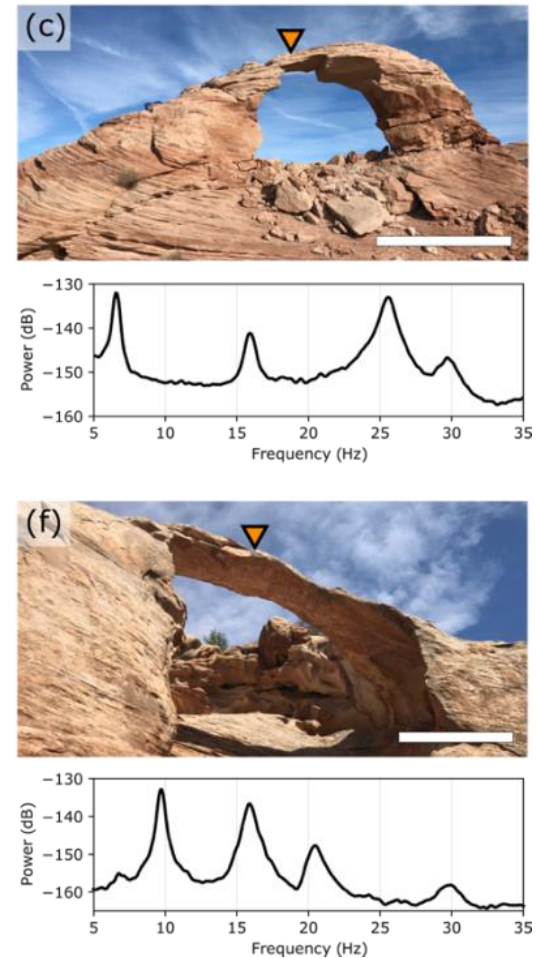

Figure 1 (a) Bell 206 helicopter (credit: Jan Ainali) and stationary infrasound frequency spectrum, with decibel amplitudes relative to 20E-6 Pa Hz${ }^{-1}$. (b) Squint Arch, (c) Arsenic Arch, (d) Little Egypt, (e) Two Bridge, (f) Big Arrowhead Arch. White bars are approximately $3 \mathrm{~m}$. Velocity spectra for the landforms are shown below each photo, with decibel powers relative to $1 \mathrm{~m}^{2} \mathrm{~s}^{-2} \mathrm{~Hz}^{-1}$. Spectra for arches show the vertical component, while spectra for hoodoos are rotated to the polarization azimuth for the respective mode. Blue triangles indicate locations of broadband seismometers, orange triangles show locations of nodal geophones. 
Table 1 Study site characteristics, including location, natural frequencies of interest, dimensions, and Young's modulus (E). Dimension A is the longest or tallest axis of each landform, B is the second largest, and C is the smallest. Note these axes are roughly mutually perpendicular.

\begin{tabular}{|l|c|c|c|c|c|c|}
\hline \multicolumn{1}{|c|}{ Site name } & $\begin{array}{c}\text { Location Lat., } \\
\text { Lon. (decimal } \\
\text { degrees) }\end{array}$ & $\begin{array}{c}\text { Resonant } \\
\text { Frequency } \\
(\mathbf{H z})\end{array}$ & $\mathbf{A}(\mathbf{m})$ & $\mathbf{B}(\mathbf{m})$ & $\mathbf{C}(\mathbf{m})$ & $\begin{array}{c}\mathbf{E} \\
(\mathbf{G P a})\end{array}$ \\
\hline Arsenic Arch & $\begin{array}{c}38.1056, \\
-110.5391\end{array}$ & 25.6 & 3 & 2 & 1 & 0.8 \\
\hline $\begin{array}{l}\text { Big Arrowhead } \\
\text { Arch }\end{array}$ & $\begin{array}{c}37.7396, \\
-110.2708\end{array}$ & $9.7,15.9$ & 7 & 3 & 1 & 2.7 \\
\hline Little Egypt 2 & $\begin{array}{c}38.0783, \\
-110.6283\end{array}$ & 25.9 & 4 & 2 & 2 & 1.0 \\
\hline Little Egypt 4 & $\begin{array}{c}38.0783, \\
-110.6283\end{array}$ & 23.8 & 4 & 3 & 2 & 1.0 \\
\hline Little Egypt A & $\begin{array}{c}38.0783, \\
-110.6283\end{array}$ & 24.2 & 4 & 1 & 1 & 1.0 \\
\hline Squint Arch & $\begin{array}{c}38.6465, \\
-110.6739\end{array}$ & $\begin{array}{c}12.5,13.8, \\
26.0\end{array}$ & 12 & 2 & 1 & 2.1 \\
\hline Two Bridge & $\begin{array}{c}37.6212, \\
-112.1639\end{array}$ & 13.7 & 9 & 3 & 1 & 5.2 \\
\hline
\end{tabular}

\section{Methods}

We first identified landforms that would likely be susceptible to infrasound emitted by common civilian helicopters. Using "infraBSU" infrasound microphones (Marcillo et al., 2012), we recorded the blade pass and higher-overtone frequencies (to

75 which we collectively refer as infrasound here for simplicity) of thickness noise from a 2-blade Bell 206 helicopter. We additionally recorded 3- and 5-blade helicopters to verify the frequency of infrasound blade pass frequency of these emitted by models according to the different number of main rotor blades (Table 2). Using broadband seismometers and $5 \mathrm{~Hz}$ nodal geophones, we recorded ambient vibration of 10 arches and 10 towers by temporarily deploying an instrument directly on each landform. The instruments recorded vibrations on average for 1-2 hours with sampling rates between $100 \mathrm{~Hz}$ and 1 kHz. Following procedures outlined by Starr et al. (2016) and Moore et al. (2018), and using methods described by Koper and Burlacu (2015) and Koper and Hawley (2010), we determined the natural frequencies of the arches and towers from these seismic recordings (Fig. 1). We confirmed the field results, following methods of Geimer et al. (2020), with numerical eigenfrequency modeling using 3D photogrammetry models of the landforms in the finite-element simulation software COMSOL Multiphysics (www.comsol.com). From the initial 20 landforms assessed, we selected the 4 arches and 3 towers 
85 with natural frequencies near $13 \mathrm{~Hz}$ or $26 \mathrm{~Hz}$ to study their vibration response during controlled flight of a Bell 206 helicopter.

We chartered several helicopter flights where we measured vibration of the arches and towers along with nearby reference sites, infrasound levels, and the helicopter's position (Fig. 2a-b). Nodal geophones and broadband seismometers sampled data between $100 \mathrm{~Hz}$ and $1 \mathrm{kHz}$, while the infraBSU microphones sampled at $200 \mathrm{~Hz}$ using a 24-bit DataCube data logger.

90 At Two Bridge (Bryce Canyon National Park, UT), the helicopter flew a standard 35-minute tourism flight over the park, with infrasound reaching the bridge at observable levels for $\sim 4$ minutes (Fig. 2c-f), while at the other sites, the helicopter performed specified maneuvers designed to vary the helicopter's speed, distance, angle, and direction for 11-25 minutes. We used a handheld GPS to measure the helicopter's position, which at Two Bridge sampled every second, while at the other sites the sampling rate varied in relation to helicopter speed (i.e. higher sampling rates at faster speeds). In processing landform vibration data, we removed each instrument's response to work in consistent units of vibration velocity and velocity-derived vibration power. The infraBSU microphones have a flat response over the $0.038 \mathrm{~Hz}$ corner frequency and a sensitivity of $4.5 \mathrm{E}-5 \mathrm{~V} \mathrm{~Pa}^{-1}$; we multiply the data by a factor of $8.744 \mathrm{E}-5$ Pa per count to convert raw data to pascals. To compare the vibration and infrasound records, we resampled each time series to a common sampling frequency, and then linearly interpolated the helicopter position data.

100 We use admittance as a measure of a landform's vibration susceptibility to helicopter-sourced infrasound. Admittance is formally defined as the ratio of a velocity vector to a force vector (Olesen and Randall, 1977), measured at the same point, as a function of frequency. Here, we represent admittance as the linearized scaling relationship between vibration velocity and infrasound pressure, considering magnitude only and not direction, to describe a landform's vibration velocity response to infrasound pressure. To calculate this value, we first selected the orientation of maximum vibration for each landform: for 105 arches, we used the vertical component of velocity, per previous modal analyses (Geimer et al., 2020), while for hoodoos, we rotated the horizontal data to the dominant polarization azimuth at the natural frequency of interest. We filtered infrasound and vibration data between 10 and $17 \mathrm{~Hz}$ or 22 and $30 \mathrm{~Hz}$ to isolate frequencies corresponding to the landform's natural frequencies and the helicopter's blade pass frequency and first overtone (i.e., 13 and $26 \mathrm{~Hz}$ ). We plotted the smoothed root-mean-square (RMS) envelope of the absolute value of arch vibration velocity as a function of the smoothed

110 RMS envelope of the absolute value of infrasound pressure, in 10-s increments with 90\% overlap, for each maneuver during the helicopter flights. We then fit these increments of data with a linear relationship and took the slope as admittance. We finally averaged all admittance values calculated for each individual helicopter maneuver. 
We also used the Doppler equation to predict the shift of infrasound frequency from the helicopter's motion (Appendix A). We obtain parameters like closest distance to arch, speed of helicopter, and time at closest distance to arch from the GPS

115 track generated onboard to predict the shifted infrasound frequencies. We used this frequency range and our 3D arch models to model arch vibration response with different energy source directions.

(a)

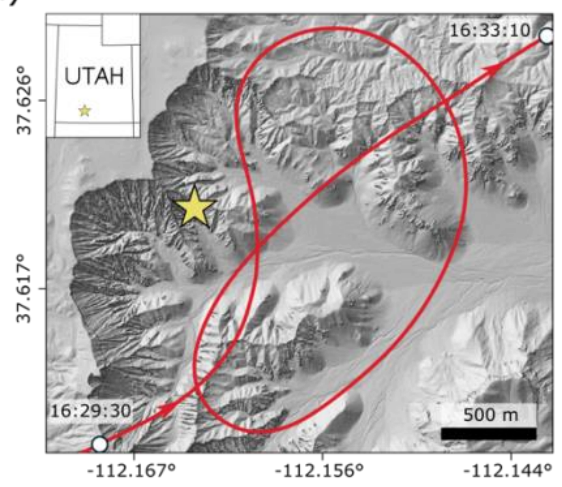

(b)

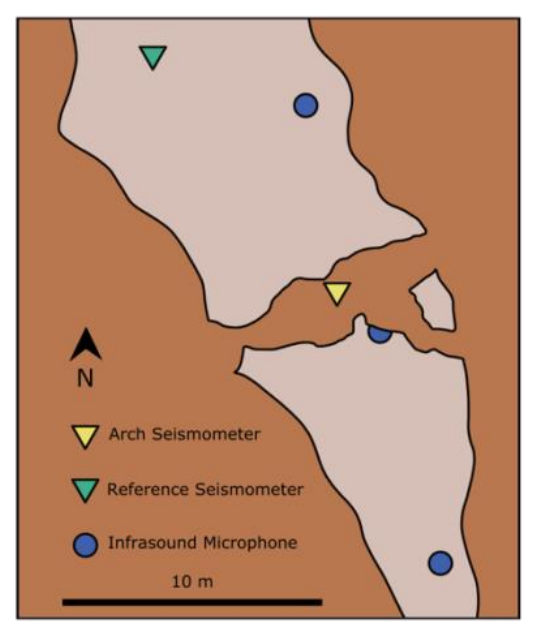

(c)

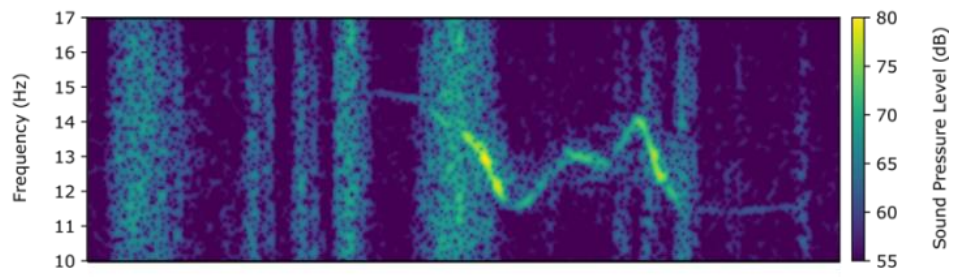

(d)

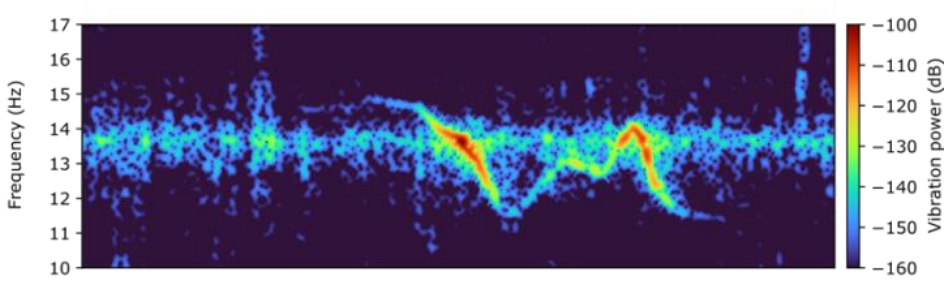

(e)

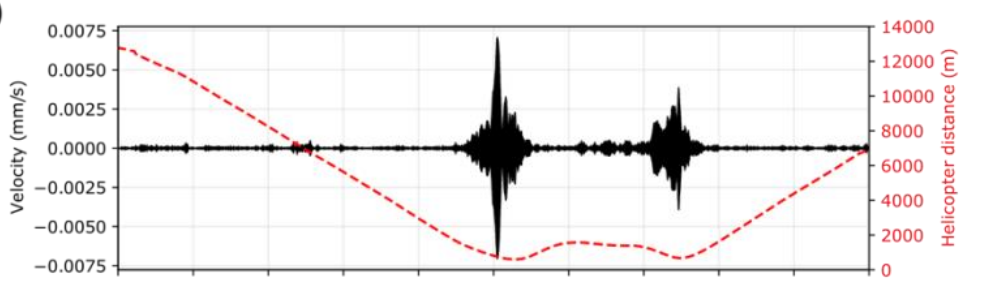

(f)

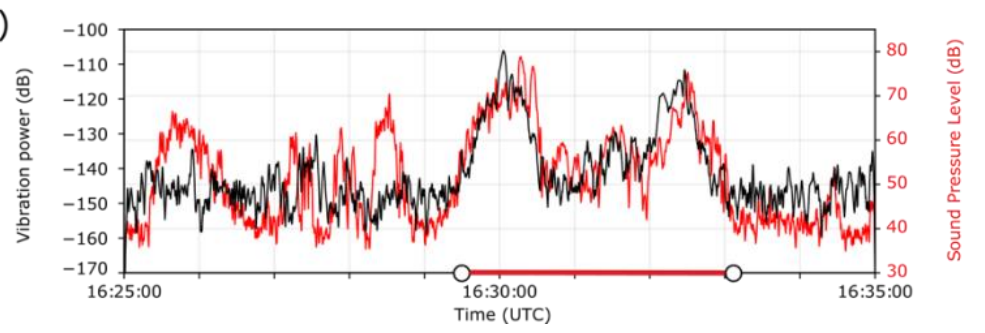

Figure 2 (a) GPS track of the tourist helicopter flight over Bryce Canyon National Park: the helicopter arrives from the south; Two Bridge location is indicated by the yellow star. (b) Overhead schematic of field equipment layout. (c) Infrasound sound pressure level spectrogram. (d) Two Bridge vibration velocity spectrogram. e) Two Bridge vibration velocity (black) 
and helicopter distance from the bridge (red) over time. (f) Arch vibration power (black) and infrasound sound pressure level (red). White circles on lower axis correspond to start and end times of the helicopter's flyover in (a). Decibel amplitudes in (c) and (f) are relative to $20 \mathrm{E}-6 \mathrm{~Pa} \mathrm{~Hz}^{-1}$ for sound pressure level, while decibel powers in (d) and (f) are relative to $1 \mathrm{~m}^{2} \mathrm{~s}^{-2}$ $125 \mathrm{~Hz}^{-1}$ for vibration power.

Table 2 Helicopter models, number of main-rotor blades, blade pass frequency and first overtone of helicopter-sourced infrasound and sound. Data are compiled from measurements made by the research team (indicated by an asterisk) and from available literature (see Moore, 2018). $\mathrm{f}_{1}$ not measured for Kaman K-1200 model.

\begin{tabular}{|l|c|c|c|}
\hline Helicopter Model & $\begin{array}{c}\text { Number } \\
\text { of Blades }\end{array}$ & $\mathbf{f}_{0}(\mathbf{H z})$ & $\mathbf{f}_{1}(\mathbf{H z})$ \\
\hline Kaman K-1200* & $\begin{array}{c}4 \\
(2 \text { sets of } \\
2)\end{array}$ & 9 & -- \\
\hline Bell UH-1 & 2 & 11 & 22 \\
\hline Bell 206* & 2 & 13 & 26 \\
\hline Robinson R44* & 2 & 13 & 26 \\
\hline $\begin{array}{l}\text { Eurocopter } \\
\text { AS350/Airbus H125* }\end{array}$ & 3 & 20 & 40 \\
\hline $\begin{array}{l}\text { Eurocopter } \\
\text { EC130/Airbus H130 }\end{array}$ & 3 & 20 & 40 \\
\hline Bell 407* & 4 & 27 & 54 \\
\hline MBB Bo 105* & 4 & 28 & 56 \\
\hline MD 500* & 5 & 40 & 80 \\
\hline
\end{tabular}

\section{Results}

We recorded infrasound from different helicopters and employed a 2-blade Bell 206 helicopter for controlled-flight field measurements. Our data confirmed that helicopter-sourced infrasound occurs at frequencies corresponding to a helicopter's blade pass frequency and integer-multiple overtones (Fig. 1a, Table 2). Our data also showed that the infrasound pressure at an observer depends on the helicopter's distance and wind conditions. We recorded peak infrasound pressure of $11.2 \mathrm{~Pa}$,

135 which corresponds to a sound pressure level of $115.0 \mathrm{~dB}$. In our tests, helicopter infrasound pressure decreased with increasing distance (Fig. B1), as anticipated for a point source of sound. 
https://doi.org/10.5194/esurf-2021-43

Preprint. Discussion started: 26 May 2021

(c) Author(s) 2021. CC BY 4.0 License.

We additionally used parameters from the helicopter's GPS track to trace the infrasound frequency shift during straight-line flight. We found the Bell 206 infrasound frequencies shifted by $\pm 15-20 \%$ from the stationary blade pass frequency and overtones, i.e., $13 \mathrm{~Hz}$ energy shifted between $11.1 \mathrm{~Hz}$ and $15.6 \mathrm{~Hz}$, and $26 \mathrm{~Hz}$ energy varied from $22.2 \mathrm{~Hz}$ to $31.3 \mathrm{~Hz}$

140 (Appendix A, Fig. A1). Other helicopter models with different speed capabilities could produce greater Doppler shift.

Arch and tower vibration velocities increased 100-1000 times during helicopter flight as compared to ambient conditions immediately prior (Figs. 2e and 3b). Maximum landform vibration amplitude during helicopter flight was between 0.007$0.13 \mathrm{~mm} \mathrm{~s}^{-1}$. Maximum admittance (slope of the best fit line between landform vibration velocity and helicopter infrasound pressure) ranged between $0.01-0.11 \mathrm{~mm} \mathrm{~s}^{-1} \mathrm{~Pa}^{-1}$ (Figs. 3 and 4). We found admittance magnitude was predominantly 145 affected by frequency alignment between helicopter-sourced infrasound and landform modal frequencies, along with distance between the helicopter and landform. Admittance was secondarily affected by landform geometry, alignment between landform modal vectors and infrasound propagation direction, and the propagation of infrasound itself. 
(a)

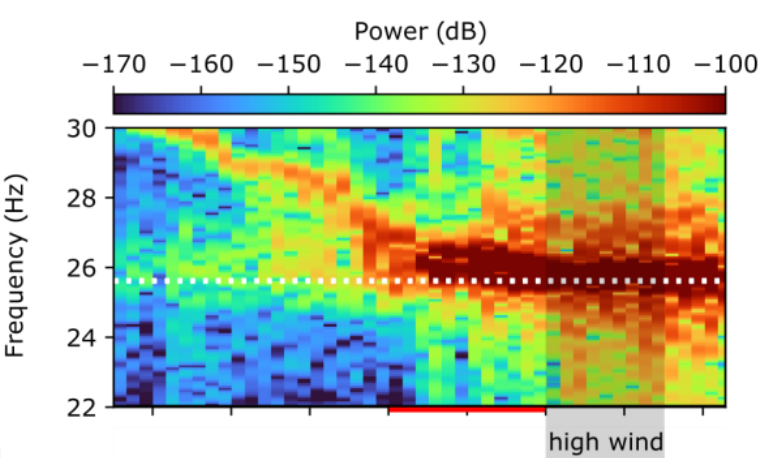

(b)

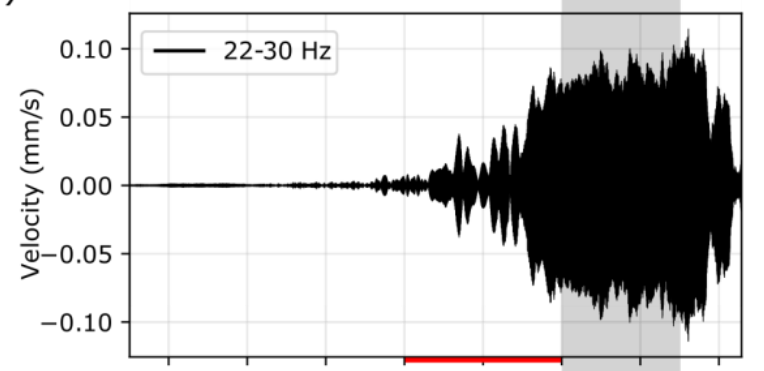

(c)

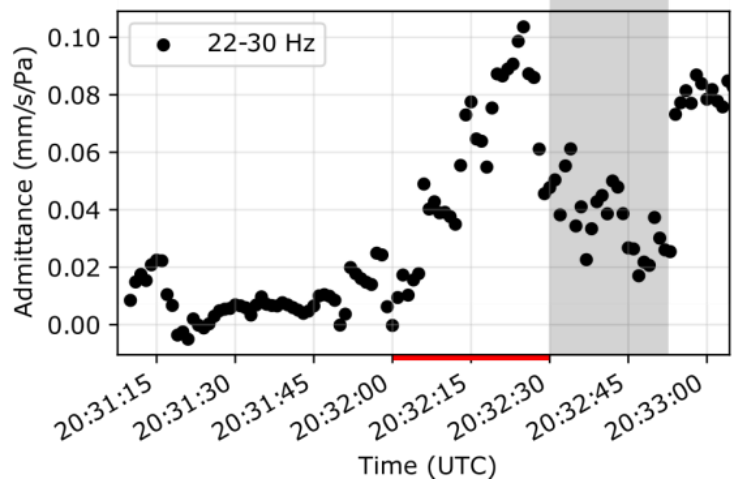

(d)

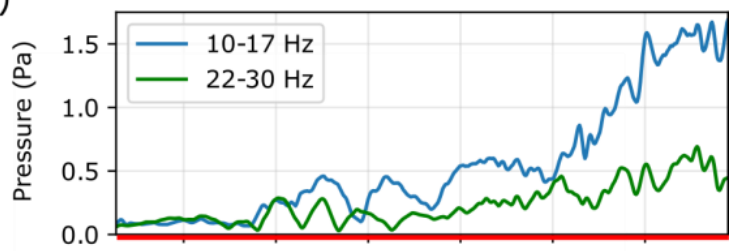

(e)

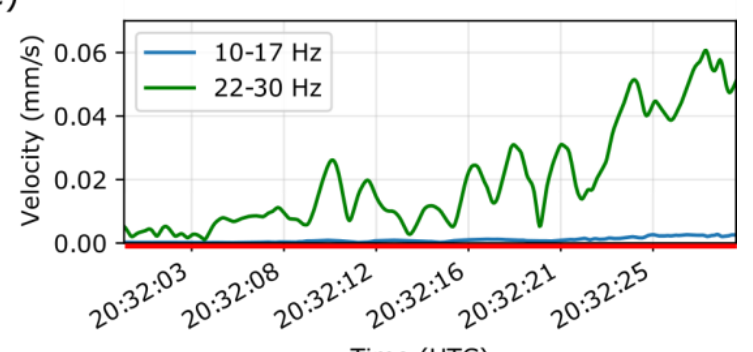

(f)

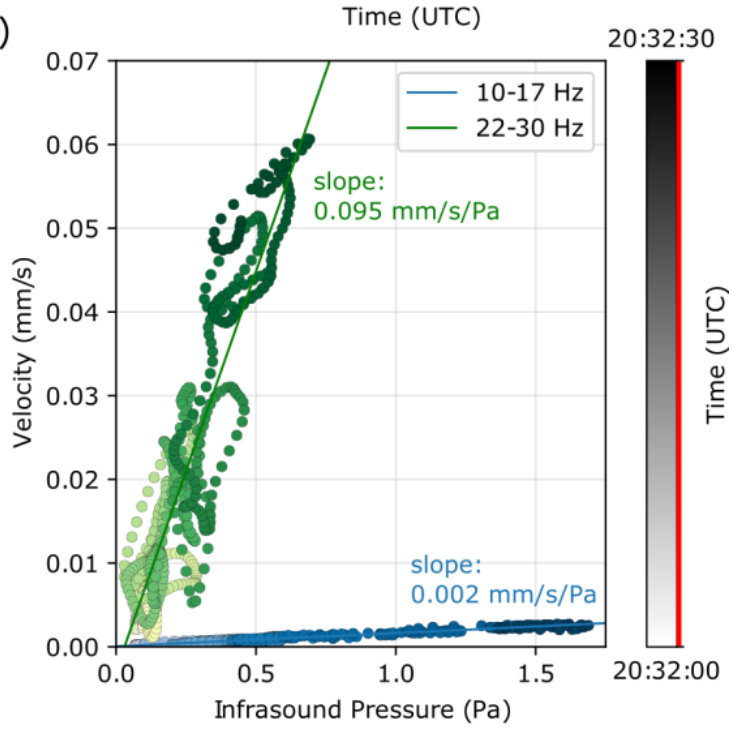

Figure 3 (a) Vibration velocity spectrogram of Arsenic Arch during helicopter approach, with decibel powers relative to 1 $\mathrm{m}^{2} \mathrm{~s}^{-2} \mathrm{~Hz}^{-1}$. Dashed line highlights the arch's $25.6 \mathrm{~Hz}$ natural frequency, which aligns with Doppler-shifted infrasound. (b) Arsenic Arch vibration velocity. (c) Arsenic Arch admittance plotted for 10 s windows with 90\% overlap. Gray shaded window in $(\mathrm{a}-\mathrm{c})$ is during high winds caused by downwash. (d) Absolute value smoothed RMS envelope of helicopter infrasound pressure. (e) Absolute value smoothed RMS envelope of vibration velocity. (f) Linear fit between arch vibration velocity and helicopter infrasound pressure, where the resulting slope is admittance. Bold red line on time axes in (a-f) indicate same time period. 
(a)

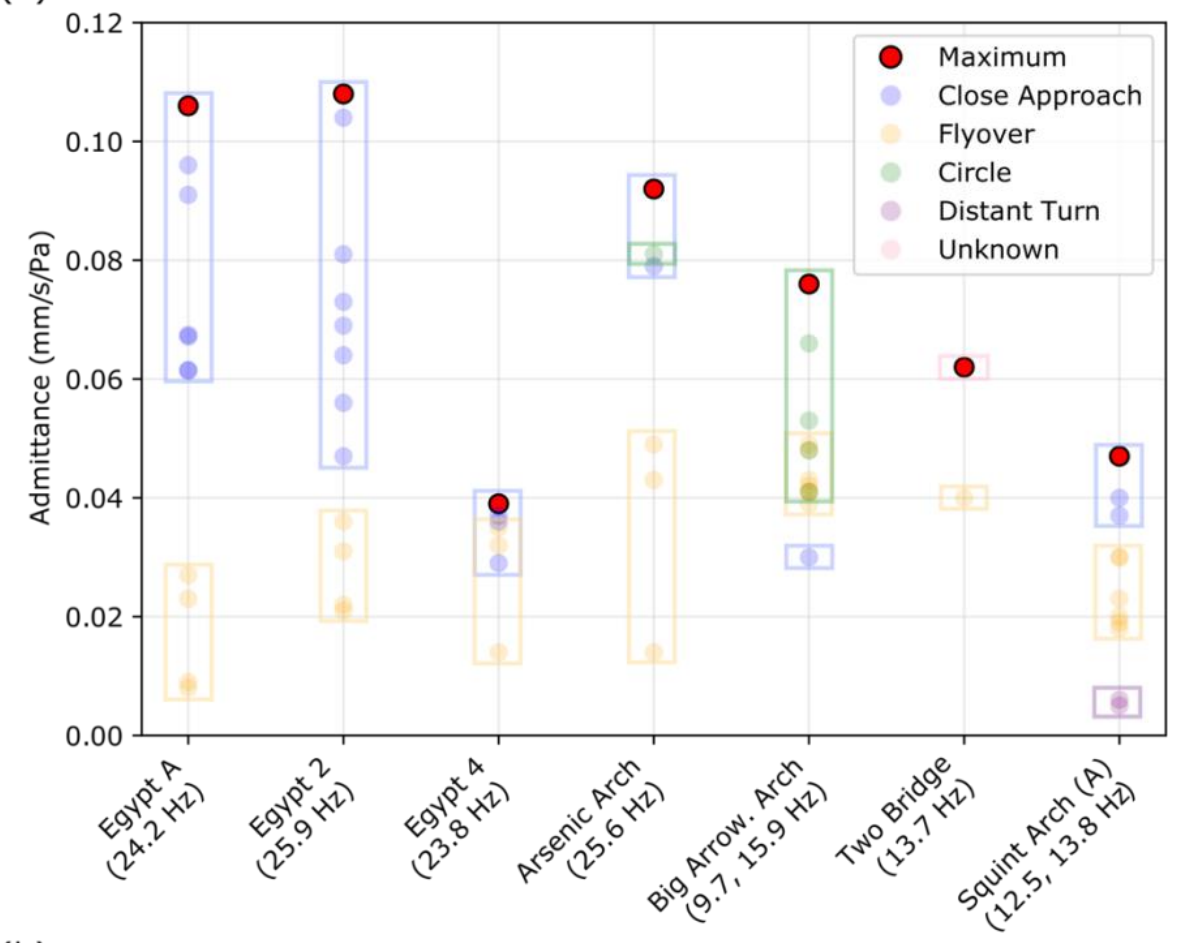

(b)

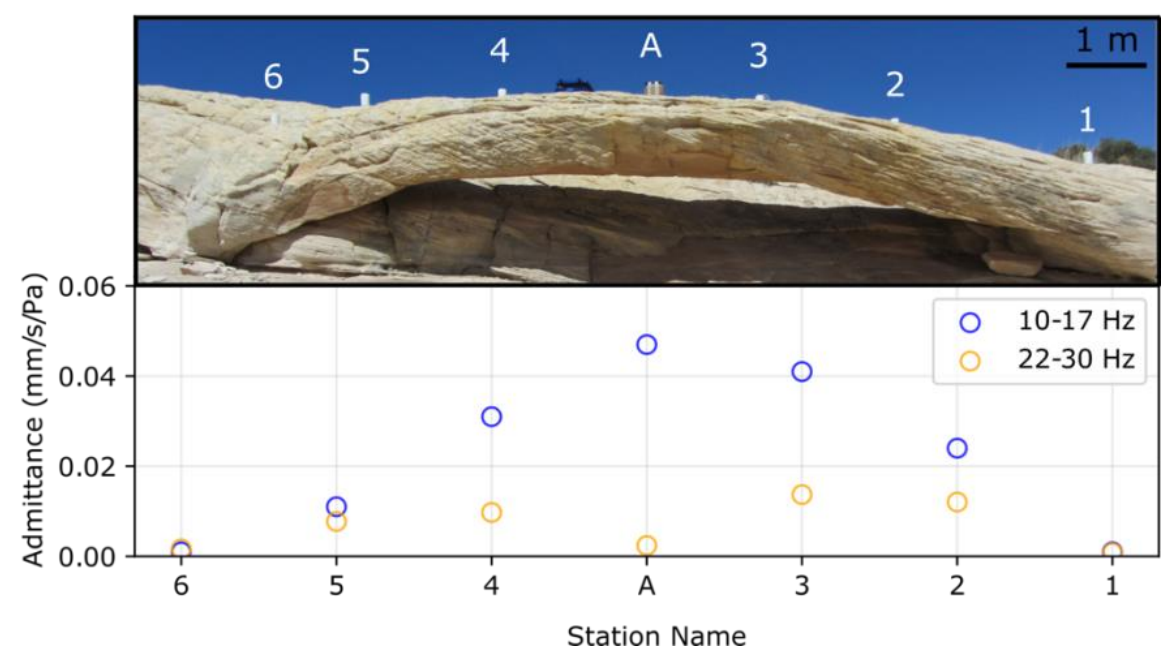

Figure 4 (a) Admittance values for different maneuvers at all study sites. Landform natural frequency excited is noted in parentheses beneath each label. (b) Maximum admittance values at different locations on Squint Arch. Numbers (nodal geophones) and letter (broadband seismometer) above the arch indicate station location. 
https://doi.org/10.5194/esurf-2021-43

Preprint. Discussion started: 26 May 2021

(c) Author(s) 2021. CC BY 4.0 License.

\section{Discussion}

\subsection{Primary factors controlling landform response}

Our data show that precise spectral alignment between helicopter-sourced infrasound frequencies and a landform's natural frequencies is one of the primary contributing factors to a landform's vibration response (Figs. 2c-d and 3a-c). This includes any combinations between the potentially Doppler-shifted blade pass frequency and higher overtones of helicopter-sourced infrasound, and fundamental or higher-order natural frequencies of the landforms.

Vibration velocity increased at all sites where Doppler-shifted infrasound frequencies aligned with the landform's natural frequencies. This demonstrates that even while infrasound pressure increases at closer distances, alignment between source and landform frequency plays a crucial role in controlling the landform response. Our field experiments included straightline flyovers, as well as turns. During both types of maneuvers, infrasound frequencies were Doppler shifted, and when these precisely aligned with the landform's natural frequencies, vibration velocity increased markedly. Tracking admittance over time during the helicopter approach at Arsenic Arch, we observed a strong increase in admittance as Doppler-shifted infrasound progressively aligned with the landform natural frequency (Fig. 3). In turn, spectral alignment between Squint Arch's $13.8 \mathrm{~Hz}$ natural frequency and Doppler-shifted infrasound when the helicopter was $2000 \mathrm{~m}$ away from the arch caused the arch to vibrate at the same velocity as when the helicopter was $350 \mathrm{~m}$ away but with poorer alignment between natural and infrasound frequencies. Two Bridge, which resonates at $13.8 \mathrm{~Hz}$, achieved peak vibration power slightly before the helicopter infrasound reached peak sound pressure level (Fig. 2f), again due to Doppler shift aligning the helicopter blade pass frequency with the bridge's fundamental frequency. We attribute the necessary precision of frequency alignment observed in our results to the relatively low modal damping ratios of these landforms (1-2\%; Geimer et al., 2020), as low damping results in narrower spectral peaks and thus a narrow bandwidth of sensitivity to input energy.

180 Landforms like Arsenic Arch and the Little Egypt hoodoos, which have natural frequencies around $26 \mathrm{~Hz}$, had highest admittance values in the $22-30 \mathrm{~Hz}$ energy band. These landforms do not have natural frequencies at $13 \mathrm{~Hz}$ and their respective admittance values in the $10-17 \mathrm{~Hz}$ band were negligible (despite high infrasound pressures in this band). Conversely, Two Bridge and Big Arrowhead Arch do not have $26 \mathrm{~Hz}$ natural frequencies, and admittance in the 22-30 $\mathrm{Hz}$ band was minor compared to admittance in the 10-17 Hz band. Squint Arch resonates at 12.5, 13.8 and $26.0 \mathrm{~Hz}$, and thus had nonzero admittance in both frequency ranges. 
Instrument placement is vital for measuring a landform's maximum admittance: measuring vibration velocity at the point of peak modal deflection provides an accurate assessment of the largest induced vibration response. Squint Arch's $26.0 \mathrm{~Hz}$ natural frequency represents a second-order bending mode, and the sensor placed at the ' $A$ ' location on the arch is at a node point (Fig. 4b). The recorded admittance at ' $A$ ' in the $22-30 \mathrm{~Hz}$ band was thus almost zero, but was highest in the 10-17 Hz band where location 'A' corresponds to maximum deflection of the fundamental mode. Results from Squint Arch also demonstrate that higher helicopter infrasound pressure emitted at $13 \mathrm{~Hz}$ versus $26 \mathrm{~Hz}$, as well as higher arch vibration velocity at a landform's fundamental frequency versus higher-order frequencies, result in greater admittance.

Admittance was largest for close-proximity, low-speed helicopter approaches where landform and infrasound frequencies aligned closely and Doppler shift was minor (Fig. 4a, Table C1). However, at Big Arrowhead Arch, which has two natural

195 frequencies on the very low and high bounds of Doppler-shifted helicopter infrasound, low-elevation hovers produced small admittance values. Instead, variable-speed circular maneuvers around the arch resulted in large Doppler shift of infrasound and higher admittance than during non-Doppler-shifted periods. The tourist helicopter flight above Two Bridge demonstrated that while close-proximity flight produces the highest landform vibration response, helicopter infrasound propagates over large distances affecting landforms over a large radius. The helicopter's closest distance to the bridge was $600 \mathrm{~m}$, yet the vibration velocity increased by a factor of more than 100 times during the flight compared to conditions immediately prior (Fig. 2e).

\subsection{Secondary influences on landform response}

Additional factors affecting landform vibration response include alignment of modal vectors with the direction of infrasound propagation, landform geometry, and environmental influences. As infrasound pressure is greatest in the plane of the helicopter's main rotor, the direction of infrasound propagation is predominantly horizontal during level flight, and precise horizontal alignment with landform modal vectors increases admittance. Helicopter approaches and hovers at the hoodoos, which have bending modes similar to that of a vertically-oriented cantilever, resulted in the highest admittance. This implies that if a helicopter maneuvered in such a way that its main rotor is perpendicular to the ground, which is uncommon, landforms with vertically-polarized modes could have higher admittance values comparable to the hoodoos. We tested this 210 using COMSOL Multiphysics, where we aligned the direction of an applied periodic force to the modal vector of a synthetic arch model, and found the arch's vibration velocity increased 7-8 times compared to the case of poor alignment. 
We attribute the relatively low admittance measured at Squint Arch to the split mode at 12.5 and $13.8 \mathrm{~Hz}$ (Geimer et. al, 2020). The modal vectors at these frequencies have similar azimuth but $60^{\circ}$ difference in incidence angle, which may result in partial destructive interference, reducing the arch's vibration response to helicopter flight. We explain the relatively low

215 admittance at Egypt 4 by considering the landform's aspect ratio (Table 1). This hoodoo is much wider than its counterparts, which contributes to greater stiffness and a reduced vibration response. Environmental factors such as topography and wind additionally affect infrasound propagation (Cheremisinoff, 1994), which can cause variations in admittance. High winds produced by helicopter downwash during landing or hovering distort the admittance, as pressure from wind is spread across a broad frequency range. We thus excluded times of windy conditions and/or excessive helicopter downwash from admittance calculations. As the helicopter settled into its hover position and wind reduced, admittance returned to a stable level (Fig. 3c).

\subsection{Significance of excitation}

Our study measured landform vibration velocities up to $0.13 \mathrm{~mm} \mathrm{~s}^{-1}$, which is an order of magnitude below levels often considered potentially damaging for ancient and culturally valuable structures as well as geologic features (Whiffin and

225 Leonard, 1971; Hanson et al., 1991; Hendricks, 2002; Andrews et al., 2013; Volpe, 2014; Moore, 2018). The measured admittance values for these landforms, however, suggest that given higher infrasound pressure, it would be possible for some of the features to experience potentially damaging vibration velocities. The highest admittance we recorded was $0.11 \mathrm{~mm} \mathrm{~s}^{-1}$ $\mathrm{Pa}^{-1}$ at the Egypt 2 hoodoo, and the highest infrasound pressure we recorded was 11.2 Pa during the Squint Arch flight: in a worst-case scenario, certain landforms could experience vibration velocities up to $1.2 \mathrm{~mm} \mathrm{~s}^{-1}$. This velocity could likely be reached for a slender tower or hoodoo with a fundamental frequency at $13 \mathrm{~Hz}$ (or the respective blade pass frequency of other helicopter models), and with the helicopter hovering or approaching slowly at a similar elevation as the landform. Modal frequencies are in turn primarily controlled by geometry, Young's modulus, and density, which reduces the number of landforms with a $13 \mathrm{~Hz}$ fundamental frequency. Thus the range of landforms susceptible to high-amplitude resonance from helicopter-sourced infrasound is likely narrow, i.e., the conditions such as frequency and modal vector alignment limit

235 the number of landforms that might experience large vibration amplitudes during helicopter flight. However, a single past study reported peak vibration velocities of $4.1 \mathrm{~mm} \mathrm{~s}^{-1}$ for a $\sim 13 \mathrm{~m}$ tall rock pinnacle (with similar values for two neighboring pinnacles), demonstrating the viability of these elevated amplitudes (King, 2001). We additionally note that heavier military helicopters not studied here likely generate higher power infrasound than lighter civilian models (Hanson et al., 1991), and further study is needed to test the effects of military helicopter overflights on the vibration response of rock landforms. 


\section{Conclusion}

We performed a series of controlled helicopter flights near several sandstone arches and towers in Utah, recording the vibration response of these landforms to helicopter-sourced infrasound. We found that landform vibration velocities were up to 1000 times greater during helicopter flight than during prior ambient conditions, with peak velocities reaching $0.13 \mathrm{~mm}$ $\mathrm{s}^{-1}$. We used the maximum measured admittance (a measure of landform vibration susceptibility to helicopter-sourced infrasound) of $0.11 \mathrm{~mm} \mathrm{~s}^{-1} \mathrm{~Pa}^{-1}$ and maximum recorded infrasound pressure of $11.2 \mathrm{~Pa}$ to present a scenario under which a landform could experience potentially harmful vibration during helicopter flight. While this scenario is limited, there are thousands of arches, towers, and other culturally significant valuable rock landforms in Utah alone (e.g., Stevens and McCarrick, 1988), and a multitude of others other nationally significant geologic features around the world. These landforms can experience helicopter overflights up to hundreds of times per day (e.g., National Park Service, 2020). Our study

250 demonstrates that helicopter blade pass frequency and higher-octave infrasound can excite resonant vibrations in rock landforms, and that landforms can be affected by helicopter-sourced infrasound when natural frequencies align with the Doppler-shifted infrasound frequency range. This recurring exposure to helicopter sound energy has implications for the landforms' structural health; our study thus provides the basis upon which further investigation into the degradation of rock landforms due to repeat exposure can be conducted.

\section{Appendix A: Doppler Shift}

Doppler shift describes how the frequency of emitted light, sound, or another wave type from a moving object is altered by the source's motion relative to a stationary observer (Doppler, 1842). As a source approaches an observer, the wave becomes effectively compressed, raising the frequency, and as a source moves away from an observer, the opposite happens and the frequency is lowered. Following methods similar to Eibl et. al (2015), Eibl, et. al (2017), and Meng and Ben-Zion (2018), we 260 analyzed the frequency shift of the helicopter-sourced infrasound from our field measurements. The observed frequency of a straight-line moving point source as a function of time is given in Eq. (1):

$$
f_{o}(t)=\frac{c \cdot f_{S}}{c+\frac{v_{S}^{2} \cdot\left(t-t_{0}\right)^{2}}{\sqrt{v_{S}^{2} \cdot\left(t-t_{0}\right)^{2}+l^{2}}}}
$$

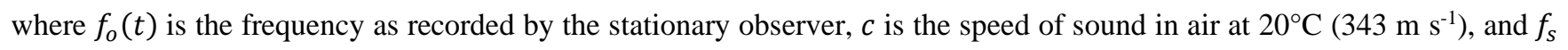
is the source frequency recorded at standstill. For a helicopter's blade pass frequency, $f_{s}$ is equal to the revolution rate of the 
265 main rotor multiplied by the number of blades. $v_{s}$ is the speed of the source, $t_{0}$ is the time at which the source is closest to the observer, and $l$ is the corresponding shortest distance.

We used parameters from the GPS track of the helicopter to calculate the Doppler shift of infrasound over time and demonstrate fit between the Doppler shift equation prediction and field measurements. We track frequency shift over time using the infrasound spectrogram: we select the frequency with the highest sound pressure level in each time window (3 s long with $90 \%$ overlap and smoothed every six points), and compare this to the resulting frequency prediction. We also fit the measured frequency shift using parameters that deliver the least amount of error, which vary slightly from the GPS parameters.

For infrasound recorded at the Squint Arch flight (Fig. A1), we use GPS parameters $v_{s}=52 \mathrm{~m} \mathrm{~s}^{-1}, t_{0}=29 \mathrm{~s}$, and $l=172 \mathrm{~m}$ to calculate $f_{o}(t)$, giving a mean squared error of $8.5 \%$. This deviation is likely caused by error from the handheld GPS. Using the best-fit parameters of $v_{s}=55 \mathrm{~m} \mathrm{~s}^{-1}, t_{0}=28 \mathrm{~s}$, and $l=135 \mathrm{~m}$ to calculate $f_{o}(t)$, we achieve a mean squared error of $1.7 \%$.

Given the maximum speed of a Bell 206 helicopter $\left(58 \mathrm{~m} \mathrm{~s}^{-1}\right)$ and the absolute minimum distance the helicopter rotor can be to an observer $(4 \mathrm{~m}=1 \mathrm{~m}$ above the ground $+3 \mathrm{~m}$ helicopter height), we find the $13 \mathrm{~Hz}$ blade pass frequency can be shifted between $11.1 \mathrm{~Hz}$ and $15.6 \mathrm{~Hz}$. Similarly, the $26 \mathrm{~Hz}$ overtone of helicopter sound energy can be shifted between $22.2 \mathrm{~Hz}$ and 31.3 Hz. These represent a $\pm 15-20 \%$ shift from the standstill frequency, demonstrating the range of landform natural frequencies possibly excited by helicopter-sourced infrasound.

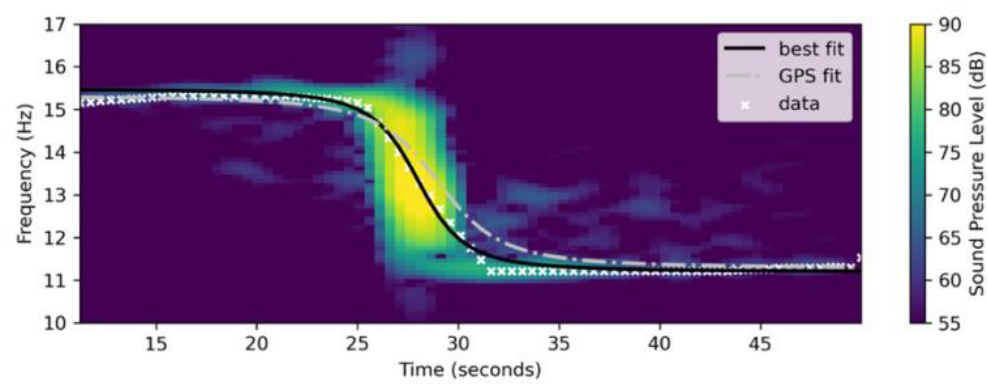

Figure A1 Doppler shift of helicopter-sourced infrasound from a Bell 206 helicopter flying above Squint Arch. Decibel amplitudes are relative to $20 \mathrm{E}-6 \mathrm{~Pa} \mathrm{~Hz}{ }^{-1}$. 
https://doi.org/10.5194/esurf-2021-43

Preprint. Discussion started: 26 May 2021

(c) Author(s) 2021. CC BY 4.0 License.

\section{Appendix B}

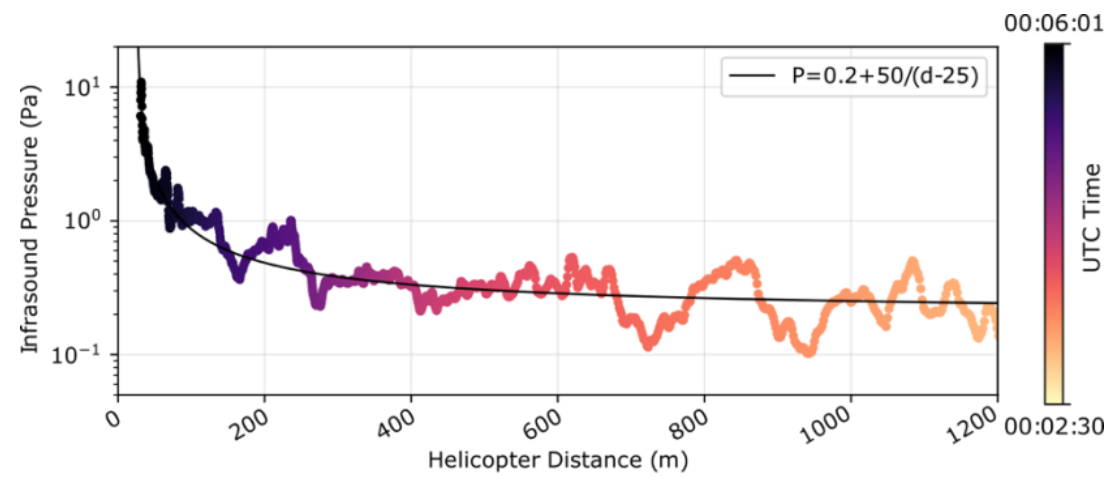

Figure B1 Inverse relationship between helicopter-sourced infrasound pressure and distance from a Bell 206 helicopter flying above Squint Arch. Data are filtered between 2 and $20 \mathrm{~Hz}$. 
https://doi.org/10.5194/esurf-2021-43

Preprint. Discussion started: 26 May 2021

\section{Appendix C}

305 Table C1 Summary of admittance values for each study site. Arch elevation and bandpass filter range provided, along with admittance averaged for each maneuver. Times for each maneuver are also listed with the direction and elevation of the helicopter relative to the landform.

\begin{tabular}{|c|c|c|c|c|c|c|c|}
\hline Site & $\begin{array}{c}\text { Arch } \\
\text { Elevation }\end{array}$ & $\begin{array}{c}\text { Bandpass } \\
\text { filter }\end{array}$ & $\begin{array}{l}\text { Admittance } \\
(\mathrm{mm} / \mathrm{s} / \mathrm{Pa})\end{array}$ & Time (UTC) & Maneuver Type & Direction & $\begin{array}{c}\text { Helicopter } \\
\text { Elevation }(\mathrm{m})\end{array}$ \\
\hline $\begin{array}{l}\text { Arsenic } \\
\text { Arch }\end{array}$ & 1463 & $22-30 \mathrm{~Hz}$ & $\begin{array}{l}0.092 \\
0.079 \\
0.081 \\
0.043 \\
0.049\end{array}$ & $\begin{array}{l}5 \text { June 2019, 20:32:25 } \\
\text { 05 June 2019, 20:32:58 } \\
\text { 05 June 2019, 20:38:02 } \\
\text { 05 June 2019, 20:34:30 } \\
05 \text { June 2019, 20:35:30 }\end{array}$ & $\begin{array}{l}\text { hover } \\
\text { hover } \\
\text { circle } \\
\text { flyover } \\
\text { flyover }\end{array}$ & $\begin{array}{c}\text { SW } \\
\text { SW } \\
N E, C C W \\
W \rightarrow E \\
W \rightarrow E\end{array}$ & \begin{tabular}{|c|}
4 \\
1 \\
13 \\
17 \\
18
\end{tabular} \\
\hline $\begin{array}{l}\text { Big } \\
\text { Arrowhead } \\
\text { Arch }\end{array}$ & 1400 & $10-17 \mathrm{~Hz}$ & $\begin{array}{l}0.030 \\
0.041 \\
0.076 \\
0.041 \\
0.049 \\
0.042 \\
0.043 \\
0.048 \\
0.039 \\
0.048 \\
0.041 \\
0.066 \\
0.053 \\
\end{array}$ & $\begin{array}{l}\text { 05 June 2019, 20:55:22 } \\
\text { 05 June 2019, 20:57:01 } \\
\text { 05 June 2019, 20:57:34 } \\
\text { 05 June 2019, 20:58:08 } \\
\text { 05 June 2019, 20:58:40 } \\
\text { 05 June 2019, 20:59:04 } \\
\text { 05 June 2019, 21:04:23 } \\
\text { 05 June 2019, 21:05:26 } \\
\text { 05 June 2019, 21:05:48 } \\
\text { 05 June 2019, 21:06:34 } \\
\text { 05 June 2019, 21:06:56 } \\
\text { 05 June 2019, 21:07:16 } \\
\text { 05 June 2019, 21:07:36 }\end{array}$ & $\begin{array}{l}\text { hover } \\
\text { flyover } \\
\text { flyover } \\
\text { flyover } \\
\text { flyover } \\
\text { flyover } \\
\text { flyover } \\
\text { flyover } \\
\text { flyover } \\
\text { circle } \\
\text { circle } \\
\text { circle } \\
\text { circle } \\
\end{array}$ & $\begin{array}{l}\text { W } \\
N \rightarrow S \\
S \rightarrow N \\
N \rightarrow S \\
S \rightarrow N \\
E \rightarrow W \\
W \rightarrow E \\
W \rightarrow E \\
E \rightarrow W \\
W, C C W \\
W, C C W \\
W, C C W \\
W, C C W\end{array}$ & $\begin{array}{l}22 \\
29 \\
24 \\
24 \\
20 \\
46 \\
27 \\
40 \\
53 \\
41 \\
46 \\
46 \\
49 \\
\end{array}$ \\
\hline $\begin{array}{c}\text { Little Egypt } \\
2\end{array}$ & 1495 & $22-30 \mathrm{~Hz}$ & $\begin{array}{l}0.056 \\
0.069 \\
0.047 \\
0.104 \\
0.073 \\
0.108 \\
0.081 \\
0.064 \\
0.031 \\
0.022 \\
0.036 \\
0.021 \\
\end{array}$ & $\begin{array}{l}5 \text { June 2019, 20:02:25 } \\
\text { 05 June 2019, 20:03:11 } \\
\text { 05 June 2019, 20:03:38 } \\
\text { 05 June 2019, 20:03:43 } \\
\text { 05 June 2019, 20:04:02 } \\
\text { 05 June 2019, 21:24:27 } \\
\text { 05 June 2019, 21:28:38 } \\
\text { 05 June 2019, 21:28:52 } \\
\text { 05 June 2019, 20:26:56 } \\
\text { 05 June 2019, 20:27:20 } \\
\text { 05 June 2019, 20:28:01 } \\
\text { 05 June 2019, 20:28:35 }\end{array}$ & $\begin{array}{c}\mathrm{N} / \mathrm{A} \\
\mathrm{N} / \mathrm{A} \\
\mathrm{N} / \mathrm{A} \\
\text { hover } \\
\text { hover } \\
\text { hover } \\
\text { hover } \\
\text { hover } \\
\text { flyover } \\
\text { flyover } \\
\text { flyover } \\
\text { flyover }\end{array}$ & $\begin{array}{c}\text { N/A } \\
N / A \\
N / A \\
S \\
S \\
S \\
S \\
S \\
N E \rightarrow S W \\
S W \rightarrow N E \\
N E \rightarrow S W \\
S W \rightarrow N E\end{array}$ & $\begin{array}{c}\text { N/A } \\
\text { N/A } \\
\text { N/A } \\
0 \\
0 \\
0 \\
\text { N/A } \\
\text { N/A } \\
37 \\
48 \\
28 \\
23\end{array}$ \\
\hline $\begin{array}{l}\text { Little Egypt } \\
\quad 4\end{array}$ & 1495 & $10-17 \mathrm{~Hz}$ & $\begin{array}{l}0.036 \\
0.037 \\
0.029 \\
0.039 \\
0.032 \\
0.014 \\
0.035 \\
0.014 \\
\end{array}$ & $\begin{array}{l}05 \text { June 2019, 20:03:17 } \\
\text { 05 June 2019, 20:03:43 } \\
\text { 05 June 2019, 20:04:18 } \\
\text { 05 June 2019, 21:28:16 } \\
\text { 05 June 2019, 20:26:56 } \\
\text { 05 June 2019, 20:27:25 } \\
\text { 05 June 2019, 20:27:54 } \\
\text { 05 June 2019, 20:28:28 }\end{array}$ & $\begin{array}{l}\text { N/A } \\
\text { hover } \\
\text { hover } \\
\text { hover } \\
\text { flyover } \\
\text { flyover } \\
\text { flyover } \\
\text { flyover }\end{array}$ & $\begin{array}{c}\mathrm{N} / \mathrm{A} \\
\mathrm{S} \\
\mathrm{S} \\
\mathrm{S} \\
\mathrm{NE} \rightarrow \mathrm{SW} \\
\mathrm{SW} \rightarrow \mathrm{NE} \\
\mathrm{NE} \rightarrow \mathrm{SW} \\
\mathrm{SW} \rightarrow \mathrm{NE}\end{array}$ & $\begin{array}{c}\mathrm{N} / \mathrm{A} \\
0 \\
0 \\
\mathrm{~N} / \mathrm{A} \\
37 \\
31 \\
23 \\
28 \\
\end{array}$ \\
\hline $\begin{array}{c}\text { Little Egypt } \\
\text { A }\end{array}$ & 1495 & $22-30 \mathrm{~Hz}$ & $\begin{array}{l}0.106 \\
0.061 \\
0.096 \\
0.091 \\
0.067 \\
0.067 \\
0.061 \\
0.023 \\
0.009 \\
0.027 \\
0.008 \\
\end{array}$ & $\begin{array}{l}5 \text { June 2019, 20:02:30 } \\
\text { 05 June 2019, 20:03:17 } \\
\text { 05 June 2019, 20:03:43 } \\
\text { 05 June 2019, 20:04:02 } \\
\text { 05 June 2019, 20:04:16 } \\
\text { 05 June 2019, 21:24:35 } \\
\text { 05 June 2019, 21:28:15 } \\
\text { 05 June 2019, 20:26:48 } \\
\text { 05 June 2019, 20:27:27 } \\
\text { 05 June 2019, 20:27:56 } \\
\text { 05 June 2019, 20:28:29 }\end{array}$ & $\begin{array}{c}\text { N/A } \\
\text { N/A } \\
\text { hover } \\
\text { hover } \\
\text { hover } \\
\text { hover } \\
\text { hover } \\
\text { flyover } \\
\text { flyover } \\
\text { flyover } \\
\text { flyover } \\
\end{array}$ & $\begin{array}{c}\mathrm{N} / \mathrm{A} \\
\mathrm{N} / \mathrm{A} \\
\mathrm{S} \\
\mathrm{S} \\
\mathrm{S} \\
\mathrm{S} \\
\mathrm{S} \\
\mathrm{NE} \rightarrow \mathrm{SW} \\
\mathrm{SW} \rightarrow \mathrm{NE} \\
\mathrm{NE} \rightarrow \mathrm{SW} \\
\mathrm{SW} \rightarrow \mathrm{NE}\end{array}$ & $\begin{array}{c}\text { N/A } \\
\text { N/A } \\
0 \\
0 \\
0 \\
0 \\
\text { N/A } \\
20 \\
22 \\
16 \\
27 \\
\end{array}$ \\
\hline Squint Arch & 1620 & $10-17 \mathrm{~Hz}$ & $\begin{array}{l}0.047 \\
0.040 \\
0.037 \\
0.019 \\
0.005 \\
0.018 \\
0.006 \\
0.020 \\
0.030 \\
0.023 \\
0.030 \\
\end{array}$ & $\begin{array}{l}\text { 01 May 2018, 00:04:09 } \\
\text { 01 May 2018, 00:04:47 } \\
\text { 01 May 2018, 00:05:21 } \\
\text { 30 April 2018, 23:46:28 } \\
30 \text { April 2018, 23:50:58 } \\
30 \text { April 2018, 23:51:56 } \\
\text { 30 April 2018, 23:53:02 } \\
\text { 30 April 2018, 23:53:55 } \\
\text { 30 April 2018, 23:55:47 } \\
\text { 30 April 2018, 23:57:15 } \\
\text { 01 May 2018, 00:01:04 }\end{array}$ & $\begin{array}{c}\text { hover approach } \\
\text { hover approach } \\
\text { hover approach } \\
\text { flyover } \\
\text { distant turn around } \\
\text { flyover } \\
\text { distant turn around } \\
\text { flyover } \\
\text { flyover } \\
\text { flyover } \\
\text { flyover } \\
\end{array}$ & $\begin{array}{c}W \\
W \\
W \\
E \rightarrow W \\
W \\
W \rightarrow E \\
E \\
E \rightarrow W \\
W \rightarrow E \\
E \rightarrow W \\
S E \rightarrow N W\end{array}$ & $\begin{array}{c}30 \\
16 \\
6 \\
52 \\
143 \\
62 \\
85 \\
39 \\
27 \\
35 \\
52 \\
\end{array}$ \\
\hline Two Bridge & 2337 & $10-17 \mathrm{~Hz}$ & $\begin{array}{l}0.040 \\
0.062\end{array}$ & $\begin{array}{l}26 \text { October } 2017,16: 30: 05 \\
26 \text { October } 2017,15: 55: 48\end{array}$ & $\begin{array}{c}\text { flyover } \\
\text { N/A } \\
\end{array}$ & $\begin{array}{c}S \rightarrow N \\
N / A\end{array}$ & $\begin{array}{l}505 \\
\mathrm{~N} / \mathrm{A}\end{array}$ \\
\hline
\end{tabular}




\section{Data Availability}

Data from this study are available at https://doi.org/10.7278/S50D-41SW-THMA.

\section{Author Contribution Statement}

The manuscript was written by RF with significant contributions from all co-authors. RF, PG, and JM acquired field data. RF a carried out data processing with contributions from PG and JM. All authors reviewed and approved the manuscript.

\section{Competing Interests}

The authors declare that they have no conflict of interest.

\section{Acknowledgements}

This study was funded by the National Science Foundation grant EAR-1831283, the University of Utah Vice President for Research, and by the Utah Science Technology and Research Initiative. We thank the Native American Consultation Committee advising Rainbow Bridge National Monument, and the Hopi, Navajo, Southern Paiute, Ute, and Zuni members therein, along with the National Park Service, for stimulating this study. Jeffrey Johnson provided invaluable support for infrasound data acquisition. Erin Bessette-Kirton, Cynthia Gardner, Ammon Hatch, Holly Hurtado, Brendon Quirk, Anna Stanczyk, Kathryn Vollinger, and Holly Walker helped with field work. Data from this study are available at https://doi.org/10.7278/S50D-41SW-THMA. The authors declare no financial conflicts of interest.

\section{References}

Aarons, S. M., Aciego, S.M., Gabrielli, P., Delmonte, B., Koornneef, J.M., Wegner, A., and Blakowski, M.A.: The impact of glacier retreat from the Ross Sea on local climate: Characterization of mineral dust in the Taylor Dome ice core, East Antarctica, Earth and Planetary Science Letters, 444, 34-44, https://doi.org/10.1016/j.epsl.2016.03.035, 2016.

Andrews, J., Buehler, D., Gill, H., and Bender, W.L.: Transportation and construction vibration guidance manual, California 330 Department of Transportation (Caltrans), Division of Environmental Analysis, Report No. CT-HWANP-RT-13-069.25.3, $190 \mathrm{pp}, 2013$.

Bass, H.E., Bolen, L.N., Cress, D., Lundien, J., and Flohr, M.: Coupling of airborne sound into the earth: Frequency dependence, The Journal of the Acoustical Society of America, 76(5), 1502, https://doi.org/10.1121/1.384312, 1980 
Broner, N.: The effects of low frequency noise on people-A review, Journal of Sound and Vibration, 58(4), 483-500, https://doi.org/10.1016/0022-460X(78)90354-1, 1978.

Cheremisinoff, P.: Human exposure to infrasound, In Encyclopedia of environmental control technology (Volume 7: HighHazard Pollutants, pp. 431-454), Gulf Professional Publishing, 1994.

Cochran, P., Huntington, O.H., Pungowiyi, C., Tom, S., Chapin, F.S. III, Huntington, H.P., Maynard, N.G., and Trainor, S.F.: Indigenous frameworks for observing and responding to climate change in Alaska, Climatic Change, 120, 557-567, https://doi.org/10.1007/s10584-013-0735-2, 2013.

COMSOL Multiphysics [Software], v5.2. www.comsol.com, COMSOL AB, Stockholm, Sweden.

Doppler, C.: On the colored light of the double stars and certain other stars of the heavens, Abhandlungen der k. böhm. Gesellschaft der Wissenschaften (5th episode, Vol. 2, pp. 465-482), 1842.

Eibl, E.P.S., Lokmer, I., Bean, C.J., Akerlie, E., and Vogfjörd, K.S.: Helicopter vs. volcanic tremor: Characteristic features 345 of seismic harmonic tremor on volcanoes, Journal of Volcanology and Geothermal Research, 304, 108-117, https://doi.org/10.1016/j.jvolgeores.2015.08.002, 2015.

Eibl, E.P.S., Lokmer, I., Bean, C.J., and Akerlie, E.: Helicopter location and tracking using seismometer recordings, Geophysical Journal International, 209(2), 901-908, https://doi.org/10.1093/gji/ggx048, 2017.

Fujino, Y., Pacheco, B.M., Nakamura, S., and Warnitchai, P. D.: Synchronization of human walking observed during lateral 350 vibration of a congested pedestrian bridge, Earthquake Engineering and Structural Dynamics, 22(9), 741-758, https://doi.org/10.1002/eqe.4290220902, 1993.

Geimer, P.R., Finnegan, R., and Moore, J.R.: Sparse ambient resonance measurements reveal dynamic properties of freestanding rock arches, Geophysical Research Letters, 47, e2020GL087239, https://doi.org/10.1029/2020GL087239, 2020.

Hanson, C.E., King., K.W., Eagan, M.E., and Horonjeff, R.D.: Aircraft noise effects on cultural resources: Review of technical literature, HMMH Report No. 290940.04-1 for National Park Service, US Department of the Interior, 1991.

Hendricks, R.: Transportation related Earthborne vibrations (Caltrans Experiences), California Department of Transportation, Division of Environmental Analysis, Technical Advisory, Vibration TAV-02-01-R9601, 2002.

King, K.W.: Investigation of helicopter induced vibrations at Balcony House, Mesa Verde, Report for the National Park Service, 1996.

360 King, K.W.: Chiricahua pinnacle vibration investigation, Preliminary report for Chiricahua National Monument, 2001

Koper, K. D., and Burlacu, R.: The fine structure of double-frequency microseisms recorded by seismometers in North America, Journal of Geophysical Research, 120(3), 1677-1691, https://doi.org/10.1002/2014JB011820, 2015.

Koper, K.D., and Hawley, V.L.: Frequency dependent polarization analysis of ambient seismic noise recorded at a broadband seismometer in the central United States, Earthquake Science 23, 439-447, https://doi.org/10.1007/s11589-0100743-5, 2010. 
https://doi.org/10.5194/esurf-2021-43

Preprint. Discussion started: 26 May 2021

(c) Author(s) 2021. CC BY 4.0 License.

Marcillo, O., Johnson, J.B., and Hart, D.: Implementation, characterization, and evaluation of an inexpensive low-power low-noise infrasound sensor based on a micromachined differential pressure transducer and a mechanical filter, The Journal of Atmospheric and Oceanic Technology, 29(9), 1275-1284, https://doi.org/10.1175/JTECH-D-11-00101.1, 2012.

Meng, H., and Ben-Zion, Y.: Characteristics of airplanes and helicopters recorded by a dense seismic array near Anza

California, Journal of Geophysical Research: Solid Earth, 123(6), 4798-4797, https://doi.org/10.1029/2017JB015240, 2018.

Moore, J. R.: Rainbow Bridge vibration risk assessment: Ambient vibration testing and computer modeling results for Rainbow Bridge, Natural Res. Rept. NPS/RABR/NRR—2018/1617, National Park Service, Fort Collins, Colorado, 70 pp, 2018.

Moore, J.R., Geimer, P.R., Finnegan, R., and Thorne, M.S.: Use of seismic resonance measurements to determine the elastic https://doi.org/10.1007/s00603-018-1554-6, 2018.

National Park Service: Reporting information for commercial air tour operations over National Park units, US Department of the Interior, 2013 Annual Report, 2016.

National Park Service: Reporting information for commercial air tour operations over units of the National Park System, US

Department of the Interior, 2019 Annual Report, Natural Resource Report NPS/NRSS/NSNSD/NRR—2020/2193, 2020.

National Park Service: Arches National Park annual park recreation visits, NPS Stats, Stats-2.7.1.17543_20191220:12:49:45, 2021.

Novoselov, A., Fuchs, F., and Bokelmann, G.: Acoustic-to-seismic ground coupling: coupling efficiency and inferring nearsurface properties, Geophysics Journal International, 223(1), 144-160, https://doi.org/10.1093/gji/ggaa304, 2020.

385 Oelsen, H.P., and Randall, R.B.: A guide to mechanical impedance and structural response techniques, Brüel and Kjaer Application Note 17-179, 1997.

Podolskiy, E.A., Genco, R., Sugiyama, S., Walter, F., Funk, M., Minowa, M., Tsutaki, S., and Ripepe, M.: Seismic and infrasound monitoring of Bowdoin Glacier, Greenland, Hokkaido University Collection of Scholarly and Academic Papers, 75, 15-36, https://doi.org/10.14943/lowtemsci.75.15, 2017.

390 Riahi, N., and Gerstoft, P.: The seismic traffic footprint: Tracking trains, aircraft, and cars seismically, Geophysical Research Letters, 42(8), 2674-2681, https://doi.org/10.1002/2015GL063558, 2015.

Schmitz, F. H., and Yu, Y. H.: Helicopter impulsive noise: Theoretical and experimental status, NASA Technical Memorandum 84390 USAAVRADCOM Technical Report 83-A-2, 1983.

Schomer, P.D., and Neathammer, R.D.: The role of vibration and rattle in human response to helicopter noise, US Army

Starr, A.M., Moore, J.R., and Thorne, M.S.: Ambient resonance of Mesa Arch, Canyonlands National Park, Utah, Geophysical Research Letters, 42(16), 6696-6702, https://doi.org/10.1002/2015GL064917, 2015. 
https://doi.org/10.5194/esurf-2021-43

Preprint. Discussion started: 26 May 2021

(c) Author(s) 2021. CC BY 4.0 License.

Stevens, D.J., and McCarrick, J.E.: The arches of Arches National Park: A comprehensive study, Mainstay Publishing, 1988.

Stoffle, R., Pickering, E., Brooks, K., Sittler, C., and Van Vlack, K.: Ethnographic overview and assessment for Arches 400 National Park, Bureau of Applied Research in Anthropology, University of Arizona, 2016.

Volpe National Transportation Systems Center, Department of Transportation: Literature review: Vibration of natural structures and ancient/historical dwellings, Internal Report for National Park Service, Natural Sounds and Night Skies Division, August, 21, 2014.

Wagner, R.A.: Helicopter noise regulations: An industry perspective, Helicopter Association of America Committee on

Helicopter Acoustic Certification Standards, 1978.

Whiffin, A.C., and Leonard, D.R.: "A Survey of Traffic-induced Vibrations," RRL Report LR418, Road Research Laboratory, Crowthorne, England, 57 pp, 1971.

Whyte, K.P.: Our ancestors' dystopia now: Indigenous conservation and the Anthropocene. Routledge Companion to the Environmental Humanities, Forthcoming, Available at SSRN: https://ssrn.com/abstract=2770047, 2016. 